\title{
Symmetrical Acrokeratoderma: A Case Report and Literature Review
}

\author{
Qing Xiao', Runke Zhou $\mathbb{D}^{\prime}$, Yu Li $\mathbb{D}^{\prime}$, Lingyun Zhao', Lidan Xiong ${ }^{2,3}$, Jie Tang ${ }^{2,3}$, Li $\mathrm{Li}^{\mathrm{I}-3}$ \\ 'Department of Dermatology, West China Hospital of Sichuan University, Chengdu, People's Republic of China; ${ }^{2}$ Cosmetics Safety and Efficacy \\ Evaluation Center, West China Hospital of Sichuan University, Chengdu, People's Republic of China; ${ }^{3}$ Sichuan Engineering Technology Research \\ Center of Cosmetic, Chengdu, Sichuan, People's Republic of China
}

Correspondence: Li Li, Tel +86 I388228574I, Fax+86 28-85422300, Email lily_hxyy@I63.com

\begin{abstract}
The current study explores a case of symmetrical acrokeratoderma, and related literature is reviewed. A 27-year-old male presented with brownish-black plaques distributed symmetrically on the dorsum of the hands and feet for 3 years, and white maceration of the lesions was observed after immersion in water. The patient was diagnosed with symmetrical acrokeratoderma, and Hirudoid ointment was topically administered twice a day for a month. The symptoms were partially alleviated, and the patient is currently under follow-up observation.
\end{abstract}

Keywords: symmetrical acrokeratoderma, differential diagnosis, keratotic, treatment

\section{Introduction}

Symmetrical acrokeratoderma (SAK) is a rare subtype of keratotic skin disease. SAK is characterized by brownish-black plaques symmetrically distributed over the dorsum of hands and feet with variable involvement of wrists, flexural surface of forearm, elbows, ankles, shin and the knee joint. The condition does not affect the palms and soles. In addition, transient and recurrent whitish maceration of lesions is observed after water contact. ${ }^{1,2}$ This type of skin disease is common in young males, and several cases have been reported in previous years among Chinese, Indian and Japanese males. ${ }^{1-4}$ In the present study, a case of symmetrical acrokeratoderma of a young male affecting both hands, wrists, feet and ankles is explored, and related literature is reviewed.

\section{Case Report}

A 27-year-old male postman, working in southwestern China, attended our hospital for treatment. The patient presented with brownish-black plaques distributed symmetrically on the dorsum of the hands and feet that had occurred in the past three years. Additionally, white maceration of the lesions was observed after immersion in water. The patient did not show any brownish-black plaques 3 years before hospitalization. Notably, the lesions worsened in warm humid summer but were alleviated in winter. Sweating or exposure to water triggered the plaques, but skin lesions disappeared after drying of the affected parts. The patient did not present any itching, pain, or other uncomfortable feelings. The patient was in good health, had no history of systemic disease, had no history of medication, had no history of hand and foot hyperhidrosis, and had no family history of hereditary diseases or a disease related to the present case.

The most distinctive clinical feature was dark brown to brownish-black pigmented keratotic lesions which were sharply demarcated, had a rough surface and were symmetrically distributed around the wrists and dorsal hands, elbows, ankles and dorsal feet (Figure 1). The patient had no symptoms of classical palmoplantar keratoderma. The lesions became white and macerated after approximately 5-minute water immersion or sweating (Figure 2), but the original features were gradually restored after drying. Physical examination did not show any abnormality in other skin and mucous membranes. 

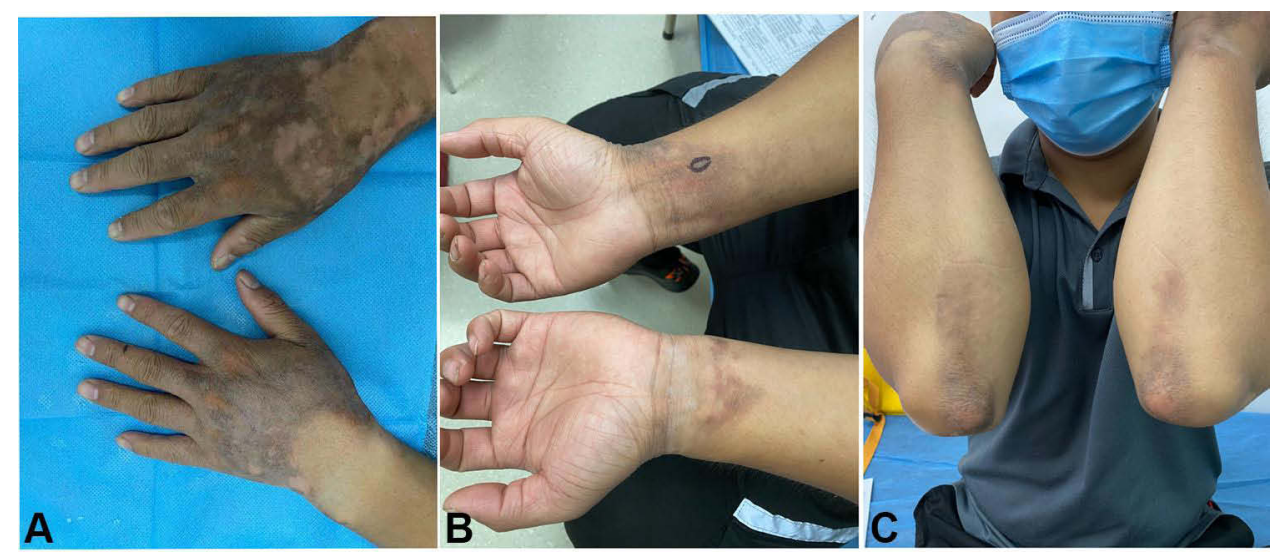

Figure I Patient with brownish-black plaque on the dorsal hands, surrounding the wrists and elbows, palms were not affected (A-C).
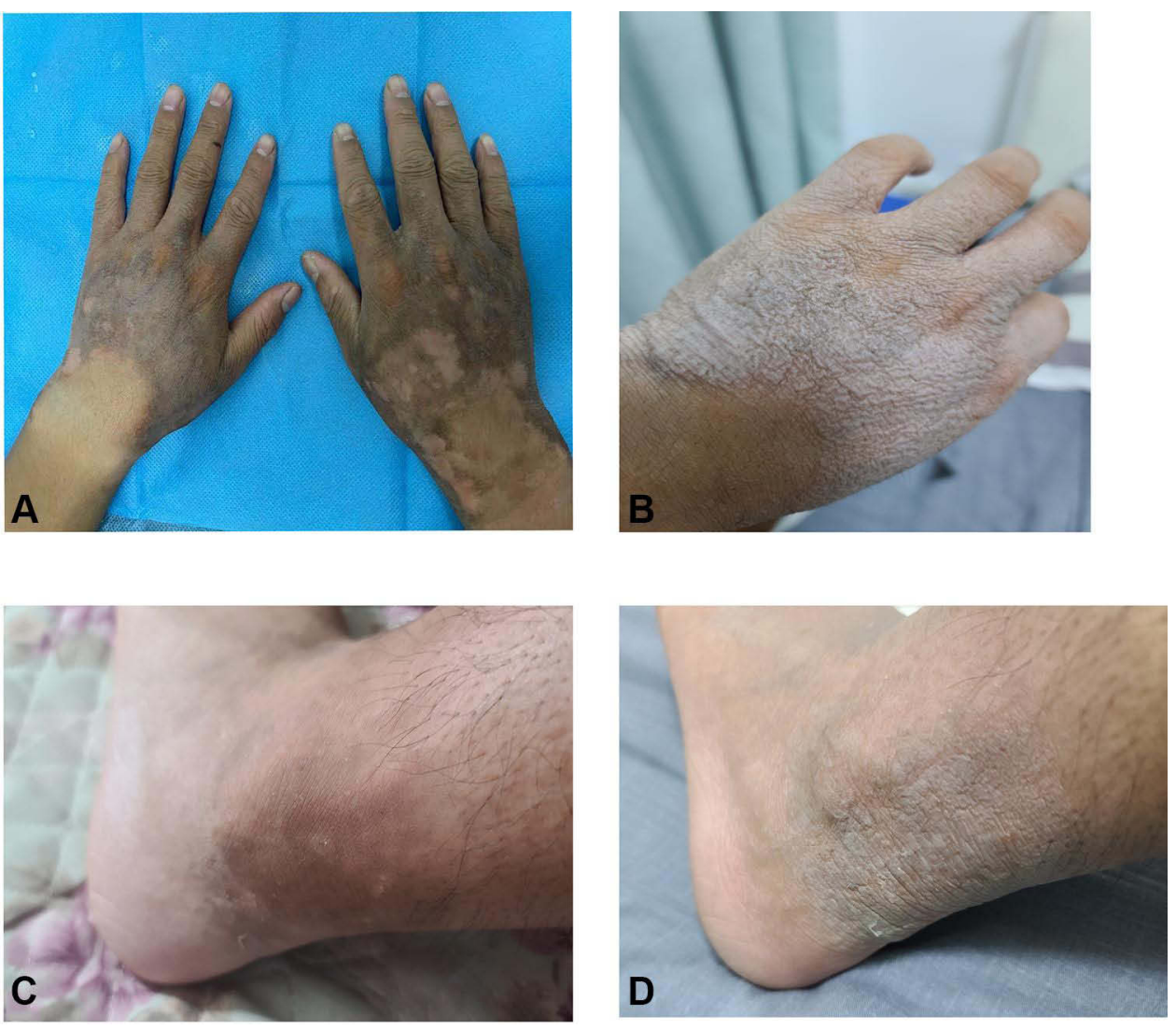

Figure 2 White maceration after immersion in water for five minutes (A-D).

Histopathological findings showed hyperkeratosis of the skin, thickening of the stratum spinosum and mild perivascular lymphocytic infiltration in the papillary layer of the dermis (Figure 3).

The patient was diagnosed with SAK based on patient history, clinical presentations, histopathological findings and features on skin after water contact. This patient underwent topical application of Hirudoid twice a day for a month, and the symptoms were partially alleviated. Figure 4 shows that the skin texture, thickness, pigmentation and extent of lesions in his hands were improved, and the previously affected area did not turn whitish after sweating or bathing. The patient is currently under follow-up observation. 

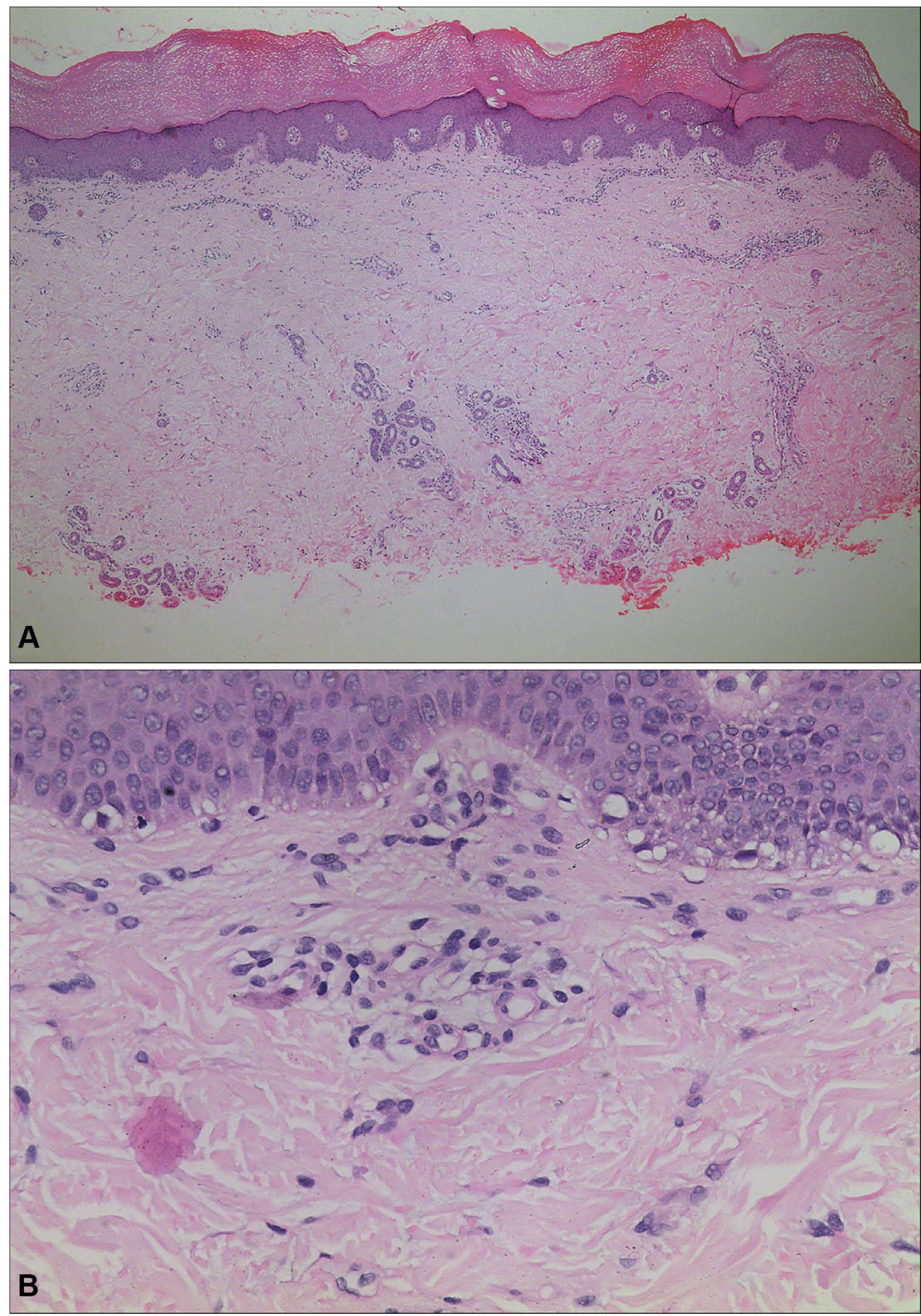

Figure 3 Histopathological findings show hyperkeratosis, thickening of the stratum spinosum (A) (H\&E, 40X) and mild perivascular lymphocytic infiltration in the papillary layer of the dermis (B) (H\&E, 200X).

\section{Discussion}

SAK is a recently described skin condition mainly observed in young adult males of Chinese descent. So far, there has been no consensus on the nomenclature of this disease. The first case report dated back to 1991 from Taiwan, but the authors mistakenly diagnosed it as acral acanthosis nigricans, supposedly based on its acral distribution and dark pigmented changes. ${ }^{5}$ Another case from Taiwan reported a 27 -year-old man with symmetrical, hyperkeratotic, brownish patches and lentigines on bilateral wrists, dorsal hands, knees and ankles in $2005 .^{6}$ Three years later, Jiang et al reported that symmetrical acral keratoderma is a newly described skin disease, in which the term "symmetrical acral keratoderma" 


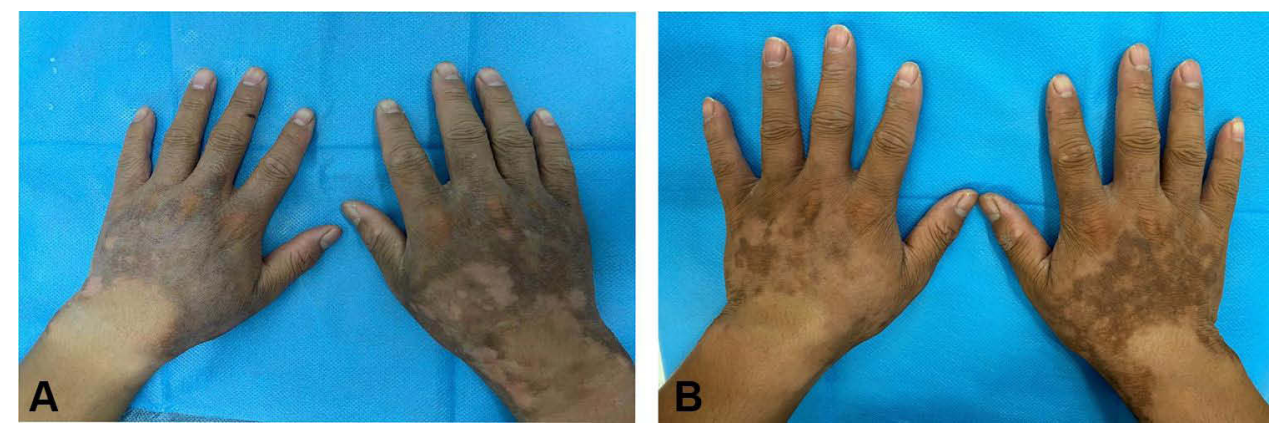

Figure 4 Topical use of Hirudoid twice a day for a month and symptoms were partially relieved (A and $\mathbf{B})$.

was proposed. ${ }^{7}$ As several cases of SAK have been reported from China, India and Japan in subsequent years, so has the discussion about naming it. Synonyms used when referring to this rare entity include pigmented carpotarsal hyperkeratosis, hyperkeratosis nigricans carpi et tarsi, and pigmented aqua-exacerbated symmetrical acral hyperkeratosis. ${ }^{6-8}$ However, some scientists think the term "pigmented aqua-exacerbated symmetrical acral hyperkeratosis" is better than "SAK" or "pigmented carpotarsal hyperkeratosis" because they hold the opinion that any proposed nomenclature should adequately describe these characteristic clinical features and the natural history of this disorder. ${ }^{8}$

SAK is clinically featured by asymptomatic brownish hyperkeratotic plaques symmetrically distributed on the acral areas, mainly on the wrists and dorsa of the hands, whereas feet, ankles, elbows, and/or knees are affected to varying degrees. ${ }^{1-3}$ Notably, the condition does not affect palmoplantar areas. Other clinical characteristics of SAK include exacerbation during summer and relief during winter and occurrence of whitish maceration immediately after water contact with restoration of the original condition after drying of the affected part. $^{2}$

Histopathological examination of samples from the affected areas shows basket weave hyperkeratosis, irregular acanthosis, mild perivascular lymphomononuclear infiltration and melanophages in the superficial and middle dermis layers. Moreover, analysis of post-immersion biopsy specimens shows loosening of the stratum corneum. ${ }^{9,10}$ In the present case, histopathological analysis of skin lesion samples indicated hyperkeratosis, thickening of the stratum spinosum and lymphocytic infiltrate at the base of the epidermis without the presence of abnormal sweat glands.

The etiology and pathogenesis of SAK have not been fully elucidated; however, several factors are implicated in pathogenesis of SAK. A gene transcription factor 4 (TCF4) mutation potentially responsible for pathogenesis of SAK in patients of Chinese descent was identified through exome sequencing, implying that SAK may be a genetic disorder. ${ }^{11}$ In addition, analysis of lesional and perilesional skin of SAK patients showed a decrease in expression level of aquaporin-3, a predominant aquaglyceroporin in human epidermis, which explains the increased transepidermal water loss (TEWL) and reduced skin hydration observed in SAK lesion. ${ }^{12}$ Other hypotheses include transitory structural or functional defects of the epidermis, resulting in increased water absorption and, subsequently, water contact reaction of SAK lesions. ${ }^{12}$

Diagnosis of SAK is mainly based on patient history, clinical presentations, histopathological findings and skin reaction after contact with water. Meanwhile, it needs to be distinguished from aquagenic acrokeratoderma, palmoplantar keratodermas and acanthosis nigricans ${ }^{6-8,13,14}$ (Table 1).

Currently, there is no specific proposed treatment for SAK. Therapeutic methods previously reported for the treatment of SAK include topical use of $10 \%$ salicylic acid ointment once a day and $10 \%$ urea cream twice a day, either applied individually or combined with use of corticosteroids. Oral acitretin with or without topical retinoic acid $0.1 \%$ gel and $10 \%$ urea can significantly improve skin texture and maceration within 4 weeks. ${ }^{4-6}$ The symptoms in the present patient were significantly alleviated after a month of topical use of Hirudoid ointment twice a day, and the patient is currently under follow-up observation. Hirudoid is the brand name of mucopolysaccharide polysulphate (MPS), and it has been used in medicine as an anti-inflammatory and antithrombotic agent for over 50 years. ${ }^{15}$ MPS includes organoheparinoid compound, hyaluronic acid and glycosaminoglycans. Its chemical structure allows considerable hydrogen to bond with adjacent water molecules, which effectively improves hydration of the surrounding tissue and prevents evaporation of water. In addition, it stimulates endogenous hyaluronate synthesis, resulting in an increase in water-binding capacity and 
Table I Differential Diagnosis of SAK

\begin{tabular}{|c|c|c|c|c|}
\hline & $\begin{array}{l}\text { Symmetrical } \\
\text { Acrokeratoderma }\end{array}$ & Aquagenic Acrokeratoderma & $\begin{array}{l}\text { Palmoplantar } \\
\text { Keratodermas }\end{array}$ & Acanthosis Nigricans \\
\hline Prevalence & Rare & Rare & Relatively common & Common \\
\hline $\begin{array}{l}\text { Individuals } \\
\text { primarily } \\
\text { affected }\end{array}$ & Young male & Adolescent female & $\begin{array}{l}\text { Middle-aged and } \\
\text { elderly }\end{array}$ & Adolescents \\
\hline Trigger & $\begin{array}{l}\text { Water contact, humid } \\
\text { summer }\end{array}$ & Water contact & Water unrelated & Water unrelated \\
\hline $\begin{array}{l}\text { Clinical } \\
\text { features }\end{array}$ & Brownish-black plaques & $\begin{array}{l}\text { Whitish papules, edema, and } \\
\text { hyperwrinkling }\end{array}$ & $\begin{array}{l}\text { Excessive thickening } \\
\text { of palms and soles }\end{array}$ & $\begin{array}{l}\text { Velvety and pigmented hyperkeratosis } \\
\text { on intertriginous areas }\end{array}$ \\
\hline $\begin{array}{l}\text { Associated } \\
\text { disorder }\end{array}$ & $\begin{array}{l}\text { Ichthyosis, palmar and } \\
\text { foot hyperhidrosis }\end{array}$ & Cystic fibrosis & $\begin{array}{l}\text { Cardiac disorders } \\
\text { or esophageal } \\
\text { carcinoma, } \\
\text { deafness, } \\
\text { periodontitis }\end{array}$ & Obesity and insulin resistance \\
\hline $\begin{array}{l}\text { Diagnostic } \\
\text { criteria }\end{array}$ & $\begin{array}{l}\text { History and clinical } \\
\text { presentations, } \\
\text { histopathologic findings } \\
\text { and skin reaction after } \\
\text { contacting with water }\end{array}$ & $\begin{array}{l}\text { History and clinical presentations; } \\
\text { positive hand-in-the-bucket sign }\end{array}$ & $\begin{array}{l}\text { Family history and } \\
\text { clinical } \\
\text { presentations, } \\
\text { histopathologic } \\
\text { findings and gene } \\
\text { testing }\end{array}$ & $\begin{array}{l}\text { Family history and clinical } \\
\text { presentations, histopathologic } \\
\text { findings and microbiology smears }\end{array}$ \\
\hline $\begin{array}{l}\text { Optional } \\
\text { treatment }\end{array}$ & $\begin{array}{l}\text { Oral acitretin; topical } \\
\text { treatment such as urea, } \\
\text { corticosteroids and } \\
\text { salicylic acid cream }\end{array}$ & $\begin{array}{l}\text { Antihistamines, botulinum toxin } \\
\text { injections, endoscopic thoracic } \\
\text { sympathectomy; topical treatment } \\
\text { such as aluminum salts and salicylic } \\
\text { acid }\end{array}$ & $\begin{array}{l}\text { Topical treatment of } \\
\text { keratolytics and } \\
\text { emollients; oral } \\
\text { acitretin when } \\
\text { necessary }\end{array}$ & $\begin{array}{l}\text { Topical drugs (retinoids, vitamin D } \\
\text { analogs, and keratolytics), oral drugs } \\
\text { (retinoids and insulin sensitizers), } \\
\text { chemical peels (trichloroacetic acid), } \\
\text { and lasers }\end{array}$ \\
\hline
\end{tabular}

viscoelasticity of the skin. ${ }^{16,17}$ These may be related to the etiological mechanism of SAK, and no studies have reported the treatment of this disease with Hirudoid. Other novel treatments such as intradermal botulinum toxin A injection $\left(\right.$ Botox $^{\circledR}$ ) have been reported to decrease sweating and improve pruritus. Meanwhile, the skin texture, thickness, pigmentation and extent of lesions were significantly improved, and previously affected area did not turn whitish after sweating or bathing after administration of therapy for five weeks. ${ }^{18,19}$

In summary, SAK is an uncommon type of keratotic skin condition mainly affecting young men of Asian descent. The disorder has not been widely explored, resulting in underreporting of incidences or misdiagnosis. Patient history, clinical manifestations, histopathological findings, water contact reaction and recovery time are important in the diagnosis of SAK. Further studies should explore the definite etiology, pathogenesis, and effective therapeutic approaches for SAK.

\section{Ethics Statement}

The authors certify that they have obtained all appropriate patient consent forms. The patient gave written informed consent for publication of clinical information and photographs. Institutional approval was not required as this is a case report and the patient had already given written informed consent for the publication of case details and the data were analyzed in a retrospective manner. 


\section{Acknowledgments}

This work was supported by grants from the Natural Science Foundation of China (Nos.81673084) and 1.3.5 project for disciplines of excellence, West China Hospital, Sichuan University.

\section{Disclosure}

The authors declare that they have no conflicts of interest in this work.

\section{References}

1. Fan YM, Li SF, Yang YP, Chen QX, Li W. Is acquired symmetrical acrokeratoderma a new dermatosis? Two case reports and Chinese literature review. Int J Dermatol. 2010;49:647-652. doi:10.1111/j.1365-4632.2009.04301.x

2. Chen W, Song Z, Young CC, Hao F. Symmetrical acral keratoderma revisited: proposal for a new term, 'pigmented carpotarsal hyperkeratosis'. $J$ Eur Acad Dermatol Venereol. 2019;33:277-280. doi:10.1111/jdv.15266

3. Vinay K, Sawatkar GU, Saikia UN, Dogra S. Symmetrical acrokeratoderma: a case series in Indian patients. Orphanet J Rare Dis. $2016 ; 11: 156$. doi:10.1186/s13023-016-0541-9

4. Nomura T, Takeda M, Jin TP, et al. Symmetrical acral keratoderma: a waxing and waning scaly pigmented skin lesions on the acral extremities. $J$ Dermatol. 2021;48:e151. doi:10.1111/1346-8138.15732

5. Chen S-Y, Liu H-T, Ho J-C. Acanthosis nigricans limited in acral areas-acral acanthosis nigricans. Dermatol Sinica. 1991;9:55-60.

6. Chen Y-T, Huang C-C. A 27-year-old man with symmetrical, hyperkeratotic, brownish patches and lentigines on bilateral wrists, dorsal hands, knees and ankles. Dermatol Sinica. 2005;23:174-175.

7. Jiang YQ, Zeng XS, Xue YN, et al. Symmetric acral keratoderma: a newly described skin disease. J Clin Dermatol. 2008;37:428-430.

8. Bishnoi A, Vinay K, Dogra S. Pigmented aqua-exacerbated symmetrical acral hyperkeratosis. J Eur Acad Dermatol Venereol. 2019;33:e187-e229. doi:10.1111/jdv.15466

9. Liu Z, Zhou Y, Chen RY, et al. Symmetrical acrokeratoderma: a peculiar entity in China? Clinicopathologic and immunopathologic study of 34 new cases. J Am Acad Dermatol. 2014;70:533-538. doi:10.1016/j.jaad.2013.10.061

10. Li CX, Han CL, Zeng K, Zhang XB, Ma ZL. Clinical, demographic and histopathological features of symmetrical acral keratoderma. $B r J$ Dermatol. 2014;170:948-951. doi:10.1111/bjd.12754

11. Chen P, Sun S, Zeng K, et al. Exome sequencing identifies a TCF4 mutation in a Chinese pedigree with symmetrical acral keratoderma. $J$ Eur Acad Dermatol Venereol. 2018;32:1204-1208. doi:10.1111/jdv.14591

12. Voss KE, Bollag RJ, Fussell N, By C, Sheehan DJ, Bollag WB. Abnormal aquaporin-3 protein expression in hyperproliferative skin disorders. Arch Dermatol Res. 2011;303:591-600. doi:10.1007/s00403-011-1136-х

13. Darlenski R, Tsankov N. Aquagenic syringeal acrokeratoderma. J Dtsch Dermatol Ges. 2012;10:198. doi:10.1111/j.1610-0387.2011.07862.x

14. Schwartz RA. Acral acanthosis nigricans (acral acanthotic anomaly). J Am Acad Dermatol. 2007;56:349-350. doi:10.1016/j.jaad.2006.09.027

15. Vecchio C, Frisinghelli A. Topically applied heparins for the treatment of vascular disorders: a comprehensive review. Clin Drug Investig. 2008;28 (10):603-614. doi:10.2165/00044011-200828100-00001

16. Kumokawa T, Hirata K, Sato K, Kano S. Dermal absorption of mucopolysaccharide polysulfate (heparinoid) in human and minipig. ArzneimittelForschung. 2011;61:85-91.

17. Wanitphakdeedecha R, Eimpunth S, Manuskiatti W. The effects of mucopolysaccharide polysulphate on hydration and elasticity of human skin. Dermatol Res Pract. 2011;2:807906.

18. Chiang C, Tsai T. Botulinum toxin type A injection in the treatment of acquired symmetrical acrokeratoderma: one case report. Dermatol Ther. 2020;33(6). doi:10.1111/dth.14442

19. Garayar Cantero M, Delgado Mucientes C, Muñoz Fernández-Lomana C. Use of botulinum toxin in the treatment of aquagenic keratoderma: one case report. Dermatol Ther. 2018;31:e12689. doi:10.1111/dth.12689

Clinical, Cosmetic and Investigational Dermatology

\section{Dovepress}

\section{Publish your work in this journal}

Clinical, Cosmetic and Investigational Dermatology is an international, peer-reviewed, open access, online journal that focuses on the latest clinical and experimental research in all aspects of skin disease and cosmetic interventions. This journal is indexed on CAS. The manuscript management system is completely online and includes a very quick and fair peer-review system, which is all easy to use. Visit http://www. dovepress.com/testimonials.php to read real quotes from published authors.

Submit your manuscript here: https://www.dovepress.com/clinical-cosmetic-and-investigational-dermatology-journal 